\title{
Drug, Food and Environmental Analysis in Rural Africa: The Need for More Action
}

\section{Adikwu MU*}

Department of Pharmaceutics, Faculty of Pharmaceutical Sciences, University of Nigeria, Nsukka

The rural population of Africa is more than $60 \%$ of the entire population with even those living in urban and peri-urban areas constituting just over $30 \%$. Even in these peri-urban and urban regions many of the people live in slums and areas that are prone to water and filth borne diseases.

In many of these areas, both rural, urban and peri-urban communities there is poor analysis of the drug, food and even the environment in which they inhabit. Over $70 \%$ of Africans depend on self-medication to meet their health needs and the need for provision of quality cannot be overemphasized [1,2]. Many of the facilities needed for these analyses are absent and thus spurious drugs and food products are easily marketed to these rural dwellers. In recent times, many farmers use herbicides in their farms. Hunters and even fishermen use chemicals to carry out their trades. This poses a lot of risks to the health of the people.

In Nigeria, for instance, various analytical methods have been developed and are being used in various research centres and higher educational institutions. Well known examples are non-aqueous titration methods [3]; use of complexing and chromogenic agents such as p-chloranil and chloranic acid [4,5]. Many of these methods are very versatile as they can be applied to a variety of drugs, food substances and even the environment. A cheap way of achieving this is to include the teaching of these simple analytical methods in curriculum of various secondary schools in Nigeria as most advanced analytical tools are found only in advanced laboratories in the urban centres either in university campuses or in research institutes. This has let the rural population to be very vulnerable to the purchase of spurious drug and food substances. The reagents and pieces needed are neither expensive nor complicated. Students at this level of education already has elements of analysis as acid-base titrations using indicators to decipher the end point is part of the syllabus. Teaching them how to analyse a few commonly consumed drug and foods products is a value addition to their education.
The impact of fake and adulterated drugs is very serious. Apart from the direct effect of inadequate therapeutic response, many microorganisms develop resistance very fast where sub-therapeutics doses have been ingested. Similarly, apart from the adverse health effects of food spurious substances, some of the herbicides used during farming may be present at such level that is deleterious to health. Similarly, where poison have been used for catching fish or for hunting of land/or bush animals the residue chemical left in the animal bodies may pose serious threats to health. In some African countries rodenticides used to check house mice have resulted to death when chickens that swallowed dead rats had enough chemicals left in their systems to kill humans when they were used for food. Another growing concern, apart from residual chemicals that can cause direct death, is the issue of microbial mutations in the environment where sub-lethal concentrations are found in the environment. Such mutations have produced very lethal organisms that may lead to epidemic in the near future. There is the need to monitor the use of these chemicals and their concentrations in the environment. All these have contributed to the very low average life span in many African countries with many countries having just 50-70 years [6].

\section{References}

1. WMA Statement on Self-medication (2012) Adopted by the 53rd WMA Genera Assembly, Washington, DC, USA, October 2002 and reaffirmed by the 191st WMA Council Session, Prague, Czech Republic, April.

2. Adikwu MU, Okoye KC (1992) Patient factors militating against the laws on prescription-only medicines in Nigeria. Nig J Pharm. 23: 7-8.

3. McGettigan P, Henry D (2011) Cardiovascular Risk with Non-Steroidal AntiInflammatory Drugs: Systematic Review of Population-Based Controlled Observational Studies. PLoS Med 8: e1001098.

4. Onunkwo GC, Adikwu MU (1995) Quantitative reactions of two amino-penicillins with $\pi$-acceptors. J West Afr Pharm 9: 40-43.

5. Adikwu MU (1996) Charge-transfer complexation of chloranilic acid with pyrimethamine. Boll Chim Farm 135: 15-17.

6. http://www.worldlifeexpectancy.com/life-expectancy-africa
*Corresponding author: Adikwu MU, Department of Pharmaceutics, Faculty of Pharmaceutical Sciences, University of Nigeria, Nsukka and currently Vice Chancellor, University of Abuja, Abuja, Federal Capital Territory, Nigeria, E-mail: michael.umale@gmail.com

Received January 09, 2015; Accepted May 27, 2015; Published July 03, 2015

Citation: Adikwu MU (2015)Drug, Food and Environmental Analysis in Rural Africa: The Need for More Action Pharm Anal Acta 6: 375. doi:10.4172/21532435.1000375

Copyright: (C) 2015 Adikwu MU, et al. This is an open-access article distributed under the terms of the Creative Commons Attribution License, which permits unrestricted use, distribution, and reproduction in any medium, provided the original author and source are credited. 